\title{
Big Data in the Field of Logistics: A Retrospective Manner to Resolve
}

\author{
Himani Sivaraman, Amit Gupta, Omdeep Gupta
}

\begin{abstract}
Big data a term created a huge change in the under currentan upcoming revolutionizing supply chain industry. The data is the new oil and gas for the modern word.SCM has also not left untouched with its Midas touch. The upcoming techniques of making decision to upgrade the profitability and data reverences. The algorithms of big data and its analytical excellence tools helped making better decisions to the upper hand decision maker and researchers .The situation of dealing a humongous and heterogenous data has been changed by these techniques. The old school SCM methods have taken a back seat in dealing these data sources. This paper is in advocacy of the present day techniques and create a path way to the explore the possibilities of the success of the big data solutions
\end{abstract}

Keywords: Supply Chain Management, Information Systems, Big data, analytics, data science,

\section{INTRODUCTION}

The major giants of the business has realized that the traditional tools and techniques they are referring in consideration with the data handling is not the party to it . The modern and promising business transformation can be only done by the Big data techniques. The inter collaboration of big data and SCM has captured the attention of many researchers, as they are hitting the headlines so, so-many practitioners also turned their head towards it. The present globalization which is involved in the new customers and their demands for changing entire old and existing business strategic models, pressurizes the industry to leave the old methods of data collection , management and presentation to the new and convincing technology and techniques of Big data.Some companies that are presently in the strategic or planning phase of supply chain management, capitalizes some bigdata business analytics tools, which help them to make strategic decision on souring Supply chain network design, as well as product design and development.( Barton, D., and Court, D. 201)

\section{THEORETICAL BACKGROUND OF DATA SCIENCE}

The conception of big data analysis is exceptional due to 3 Vs that is variety, velocity and volume of the data, which in present scenario are easily available and not so expensive to access and to store this diverse data.( M. Jeseke,2013) The occurrence in regards to data can have a variety of ways.

Revised Manuscript Received on November 25, 2019.

Himani Sivaraman, Department of CSE, Graphic Era Hill University, Uttarakhand, India. E-mail: himanisivaraman@gmail.com

Amit Gupta, Department of CSE, Graphic Era Hill University, Uttarakhand, India. E-mail: amitgupta7920@gmail.com

Omdeep Gupta, School of Management, Graphic Era Hill University, Uttarakhand, India. E-mail: omdeepg@gmail.com
The data is captured in more details (S. Ghemawat,2003). The IT sector of the organization, finds many more solace for solution based on Hadoop and MapReduce. The circumstantial evident about dealing with this humongous amount of data have not been imprecise. The data which is presently available is often accumulated in huge flat files. All these files are altered into easy to get to structured format of data as they are stipulate by these traditional databases. If the further usage is planned then the transformation is obligatory. Big data have two most important perspectives one is analytics, which is considered as the backbone for big data processing. BD refers to high velocity, large volume, and wide variety of datasets of dynamically generated data which exceeds the processing capabilities of previously used data management techniques. The various techniques in Big Data have to be adapted by the companies necessities according to the environment. Data for each venture is entity due to different semantics denotation and structure changing not only between dissimilar organizations, but also within department and its division.( T. Berners-Lee, et al,2001) One of the main challenge of nowadays IT organizations is dealing with the big data which is generating in huge amount is to make sure the ease of use of storage space and resourceful accessibility. This real time data disembark irregularly. This inward data has to be handled in a real-time environmentregularly. The main issue is the value of this data. This is to be related to the prime fact about this data that it is requires to be processed and analyzed for further usage.

The required data sources, are alienated mainly into two categories i.e. internal data and external data. The datasources gets it internal data mostly gets originate in industry IT system and databases. Besides that, the external data sources originate from social media platforms, and data sets on portals. (Julian SK Tan, Ai Kiar Ang, Liu Lu, et al ,2016.) Social media data sources are not directly reachable, apart from being unstructured most of thetime

\section{A. The road so far}

The researches are popularly taking interest in the BDA intersects SCM and its advance analytical techniques resolving the operational issues. In 2014, at the annual conference of Council of Supply chain management, Sanders(2014) published his book, combing the intersection of Big data and supply chain management . along with the managerial implication of it.

The biggest confrontation in analysis is to analyze asymmetrical-proceeding data, and the presently accessible data in the given datasets. (Anoop Kumar Sahu ,2017) 


\section{Big Data in the Field of Logistics: A Retrospective Manner to Resolve}

The Statistical approach towards SCM is a excellent approach, but predictive analytics is the approach which mainly take on quantitative and qualitative predictions. The process of predicting the future is termed as forecasting and in case of predictive analysis we normally add questions on the subject of 'what would have happened in the past' on the basis of different conditions.(Welt,2017)Optimization is a process of ruling the maximum or minimum of a function which have non dominating sets, subject to constraints. The relationships between the various parameters is clearly described by the predictive analysis which attempts to use dedicated mathematical methods effectively to come to any conclusion.(Ivan Varela Rozados, 2014)

\section{B. The impact of Advance Analytics on logistics}

Advance analytics is basically a method or a technique to bring out a better decision by transforming data and making it more maintainable and more acceptable for the future use of the organization. On continuation to it, the descriptive analytics is a technique to make a decision from the past patterns, expectations and trends. Predictive analytics is another technique which is in trend and being used by many of the researchers to make a level orientation for the logistics and supply chain management. Along with the real time data the past data is also brought into consideration for the judgement of data and making better decision and operational strategy.

The encompassed techniques are being able to take full strategic impact from machine learning algorithms as well as other data mining algorithms . Algorithms like, k-NN, Naïve Bayes, discriminant analysis etc. are some of the few of it, which have become a backbone of the analytical techniques in it.

\section{Smart benefits in logistics}

The business communication are evaluated and analyzed having a collection for peripheral data and to acknowledge its description to the supply chain network (A. Katal,2013). The many data analytics algorithms and tools make the supply chain data more rodent and robust.. The modern data analytical techniques channelizes this data into more sequential and more structured manner.

As the market is growing the expectation, competition and unpredictability is growing, the companies along with the retailers are exploring the opportunities through data analytics to address these new challenges. The analytical techniques not only provide them with greater scope of accuracy, clarity and a huge insight but also lead to more "appropriate Intelligence" regardless which area or industry the supply chain belongs to. (Julian SK Tan,2016)Various data sources related to SCM are mostlyunderwentand unstructured in nature that are crucial and hard to analyse with the use of conventional IT methods .

The Big data analytics modelling can engender revenue streams and create its more valuable business models(Ivan Varela Rozados,2014). Efficient decision making techniques and high performance can be achieved by big data capabilities. The big data techniques can enhance not only supply chain of an organization such as sales human resources and in marketing too.

Bigdata business analytics can be vastly applied in supply chain operation, such as demand planning, procurement ,production ,inventory management, demand forecasting , and this can improve the overall supply chain performance in an organization(Gang Wang a,2016)

\section{Practical Implementation of BDA and SCM}

This part of this review paper tends to imply to provide support to researchers to comprehend where they can integrate BDA through out supply chain, along with potentially and practically solve this complex problems in lieu to SCM . Our understanding for the SCM main activities buy, sell, move, and store; its levers are procurement, marketing, transportation, and warehousing, operations. The Table 1 will give a insight to the practical implementation of BDA in SCM with the help of these levellers.

\begin{tabular}{|c|c|c|c|}
\hline LEVERS & Types of Data & BDA proposed Methods & BDA Techniques used \\
\hline Marketing & $\begin{array}{l}\text { Advertisements, ratings, } \\
\text { reputation by third party, } \\
\text { Web logs } \\
\text { Feeds, } \\
\text { Customer surveys }\end{array}$ & $\begin{array}{l}\text { - Integrating all the data sources which } \\
\text { relate to product } \\
\text { - Use supervised learning methods and } \\
\text { algorithms to predict the demand } \\
\text { based on the training dataset. }\end{array}$ & $\begin{array}{c}\text { NLP } \\
\text { Text Mining } \\
\text { Logistic Regression } \\
\text { Random Forest }\end{array}$ \\
\hline Procurement & $\begin{array}{l}\text { SRM truncation data, } \\
\text { Top customer } \\
\text { Supplier financial } \\
\text { performance information }\end{array}$ & $\begin{array}{l}\text { - Fetching the performance } \\
\text { requirement report SLA or other } \\
\text { quality measures for procurement } \\
\text { contract renew. } \\
\text { - Capturing data regarding previous } \\
\text { transaction of the supplier with } \\
\text { respect to delivery, locations, lead } \\
\text { times. }\end{array}$ & $\begin{array}{c}\text { Expert system modelling } \\
\text { KNN } \\
\text { Naïve Bayes }\end{array}$ \\
\hline
\end{tabular}




\begin{tabular}{|c|c|c|c|}
\hline $\begin{array}{l}\text { Warehouse } \\
\text { operation } \\
\text { methodology }\end{array}$ & $\begin{array}{c}\text { IOT sensing } \\
\text { User demographics }\end{array}$ & $\begin{array}{l}\text { - Detectingvarious sources in real } \\
\text { time fashion with reports } \\
\text { generated on supervised assets } \\
\text { together with use demographics } \\
\text { liabilities. } \\
\text { - Cluster creation on the basis of } \\
\text { usage patterns and users }\end{array}$ & $\mathrm{t}-\mathrm{SNE}$ \\
\hline $\begin{array}{c}\text { Transportation \& } \\
\text { logistics }\end{array}$ & $\begin{array}{c}\text { Traffic density, } \\
\text { Weather, } \\
\text { ITS, } \\
\text { GPS-enabled telematics }\end{array}$ & $\begin{array}{l}\text { Time variability of delivery in a pre- } \\
\text { defined network model, update in } \\
\text { delivery unit } \\
\text { Network availability factors to account } \\
\text { on Spatial regression Delivery pointer }\end{array}$ & $\begin{array}{c}\text { Spatial Regression } \\
\text { modelling }\end{array}$ \\
\hline
\end{tabular}

So, by this Table we can say that SCM Big data analytics is a procedure of smearing the $\mathrm{BDA}$ techniques in amalgamation with the SCM theory of variety of information, velocity and volume of diverse data. In lieu to SCM professionals to sense and equally respond on the providing of solutions and timely insight business methods. Demand forecasting have two prominently specific methods, which emphasize the researchers to select more effectively appropriate method. The impact of SCM levers on various industry are too strong. The strength of these levers and their data sources create a huge plunge in the industry and as well as within the organization .

The SCM huge data cannot be commonly generated by the unstructured formats of the old and tradition IT management tools. It take a lot of consideration for theses IT tools to generate a correlation between asymmetric data of the SCM and relatively small amount of tools and techniques .

Techniques like GPS transponders, RFID data identifiers and other consistent data transponders create great deal of aggregation of timeliness, accuracy, completeness and consistency in the data maintenance

\section{CONCLUSION}

The main requirement for Supply chain management are these new techniques to channelize the data as well as these lower the complexities because these techniques. It is now a staunch believe among the industry of supply chain that the new possibilities and creativity can enhance ways for big data creating design model, relationship development,the customer service system, and manage day-to- day value added operation of Supply chain management. We can also conclude that the data has become more of a strategic asset than a informational liability. Let the data be from internal or external sources, it will be considered more appropriate ways to solve these issues and help it in making a better business design model for supply chain management. In this paper we have inferred the strategic and functional importance of big data methods and techniques on SCM.

\section{REFERENCES}

1. Jens Leveling, Matthias Edelbrock, Boris Otto," Big Data Analytics for Supply Chain Management", 12 March 2015, 2014 IEEE International Conference on Industrial Engineering and Engineering Management 978-1-4799-6410-9

2. Matthew A. Waller and Stanley E. Fawcett, Data Science, Predictive Analytics, and Big Data: A Revolution That Will Transform Supply Chain Design and Management", Journal of Business Logistics, 2013, 34(2): 77-84 Council of Supply Chain Management Professionals.
3. Anoop Kumar Sahu, Saurav Datta, S.S. Mahapatra. "Evaluation of performance index inresilient supply chain: a fuzzy-based approach",Benchmarking: An International Journal, 2017

4. Ivan Varela Rozados, Benny Tjahjono, "Big Data Analytics In Supply Chain Management:Trends And Related Research", 6th International Conference on Operations and Supply Chain Management, Bali, 2014

5. Smart Service Welt Working Group, "Smart Service Welt:Recommendations for the Strategic Initiative Web-based Services for Businesses", acatech, Berlin, 2014.

6. M.Jeseke, M. Grüner, F. Wieß, "BIG DATA IN LOGISTICS: A DHL perspective on how to move beyond the hype", DHL Customer Solutions \& Innovation, 12.2013

7. S. Robak, B. Franczyk, M. Robak, “Applying big data and linked data concepts in supply chains management," 2013 Federated Conference on Computer Science andInformation Systems (FedCSIS), pp. 1215 1221,201

8. A. Katal, M. Wazid, R. H. Goudar, "big data: Issues, Challenges, Tools and Good Practices", IEEE Sixth International Conference on Contemporary Computing (IC3), pp. 404-409, 08.2013

9. S. Ghemawat, H. Gobioff, S.T. Leung, "The Google File System", ACM SIGOPS Operating Systems Review, ACM, pp. 29-43, 08.2003

10. T. Berners-Lee, et al., "W3C Semantic Web Activity" [Online]. Available: http://www.w3.org/2001/sw, 2001

11. Sanders, N. R. (2014). Big Data Driven Supply Chain Management: A Framework for Implementing Analytics and Turning Information into Intelligence, 1st Ed, Pearson, NJ 